\title{
Efficiency of pre-sowing seeds by UV-C and X-ray exposure on the accumulation of antioxidants in inflorescence of plants of Matricaria chamomilla $L$. genotypes
}

\author{
Vladyslav Zhuk ${ }^{(1}$, Daryna Sokolova ${ }^{\circledR}{ }^{*}$, Alexandra Kravets ${ }^{(1}$, \\ Volodymyr Sakada(i), Ludmila Glushenko ${ }^{(2)}$, Mykola Kuchuk (iD)
}

\begin{abstract}
${ }^{1}$ Institute of Cell Biology and Genetic Engineering, National Academy of Sciences of Ukraine, Kyiv
${ }^{2}$ Experimental Station of Medicinal Plants of The Institute of Agroecology and Nature Management, National Academy of Agrarian Sciences of Ukraine, Lubny
\end{abstract}

\begin{abstract}
Secondary metabolites of the medicinal plants are among the main active substances of the drugs used in medicine. An important place among them belongs to phenols and flavonoids, which are some constitutive components of the redox homeostasis maintaining system through the animal and plant organisms.

Radiation exposure is one of the most powerful factors leading to the oxidative stress, stimulating the formation of radioprotectors with antioxidant, anticancer, immunomodulatory, and anti-inflammatory effects. The data presented in the previous report indicated some differences in the pharmaceutical raw material yield stimulation of various genotypes under UV-C and X-ray exposure. This stage of the study is devoted to the investigation of the stimulating the yield of flavonoids and phenols as the markers of the secondary metabolism reorganization.

The differences in the dynamics of the flavonoids and phenols content in plants of eight genotypes of the chamomile in the control and under pre-sowing UV-C and $\mathrm{X}$-ray radiation exposure of seeds were studied. Groups of the genotypes by the stimulating effect on the content of antioxidants were determined mainly under UV-C exposure, as well as groups with a significant increase in the content of antioxidants under X-ray exposure were identified. A highly significant correlation $(R=0.84)$ between the stimulation of the flavonoid synthesis under X-ray exposure and the level of these antioxidants in the control is shown. Above average $(\mathrm{R}=$ 0.64 ) insignificant correlation is observed between the flavonoids level under UV$\mathrm{C}$ exposure and in the control variant.
\end{abstract}

\section{ARTICLE HISTORY}

Received: Mar. 02, 2021

Revised: June 05, 2021

Accepted: June 20, 2021

\section{KEYWORDS}

Antioxidants, Non-targets effects, Pharmacology, UV-C exposure, $\mathrm{X}$-ray exposure.

\section{INTRODUCTION}

Enzymatic and non-enzymatic antioxidants are constitutive components of the redox homeostasis maintenance system in the animal and plant organisms (Kretovich, 1986; Kudryashov, 2001; Croft, 1998). The antioxidant system also plays an active protective role under the biotic and abiotic stressors effect (Kudryashov, 2001; Winkel-Shirley, 2002; Treutter, 2006; Mittler, 2002).

\footnotetext{
*CONTACT: Daryna Sokolova $₫$ dasokolova88@gmail.com Engineering, National Academy of Sciences of Ukraine, Kyiv
} Institute of Cell Biology and Genetic 
Radiation exposure is one of the most powerful factors of the oxidative stress and stimulates radioprotectors formation (Kudryashov, 2001; Mittler, 2002; Khattak \& Simpson, 2008), which has some antioxidant, anticancer, immunomodulatory, and anti-inflammatory effects (Alothman et al., 2009; Harrison \& Were, 2007; Dai \& Mumper, 2010; Moghaddam et al., 2011; Kaur \& Mondal, 2014).

Biotechnology uses radiation exposure for the reorientation of the plant metabolic processes to achieve the desired direction for the practice based on the systematic defense reactions. Formation of non-target effects such as the induction of protective and adaptive reactions in non-exposed organs of the organism («abscopal effect») and even in non-exposed organisms that are found in the same environment as exposed ones («by stander effect») (Sengul et al., 2009; Kuzin, 1970; Little, 2007; Kravets et al., 2009) enables the products of the plant protective reactions in non-exposed structures, which are some medicine material (Gould \& Lister, 2006).

The data presented in the previous report indicated some differences in the pharmaceutical raw material yield stimulation of various genotypes under UV-C and X-ray exposure (Sokolova et al., 2021). The genotypes were differing not only with the medicinal raw material yield but also with the flowering dynamics under different types of radiation exposure. The next stage of the study is devoted to the investigation of the stimulating effective secondary metabolism of the chamomile under seeds pre-sowing UV-C and X-ray exposure. The yield of non-enzymatic antioxidants, such as flavonoids and phenols, was used as the marker of the secondary metabolism reorganization.

Despite the diversity of the functions of these compounds, which are involved in a number of blocks of primary plant metabolism such as photosynthesis, the formation of lignin and suberin of the cell walls, plant biochemistry classifies them as the products of secondary metabolism (Kretovich, 1986) playing role of some protective agents in the plant pathogenesis. Plant and animal biology considers them as some low-molecular antioxidants and the most essential components of the endogenous radiosensitivity background (Kudryashov, 2001). Currently they are widely used in medicine as the oncoprotectors for the treatment of inflammatory processes and diseases of the vascular system (Alotman et al., 2009; Aziz et al., 2015; Cermak \& Wolffram, 2006; Clark et al., 2015).

The study focused on the analysis of key issues of the biotechnology development:

- the assessment of the initial level of the antioxidants through the different genotypes;

- the intensity of their response to a particular type of radiation exposure;

- the correlation assessment of the indexes and the comparative evaluation of the target metabolite dynamics in the control and under the exposure.

\section{MATERIAL and METHODS}

The research was done using 8 genotypes of Matricaria chamomilla. Six certified varieties of the different origin were used: 1 - the generative generation of the mutant Perlyna Lisostepu (treated with the herbicide RaudAr in concentration 10); 2 - the variety Quedlinburg (Germany); 3 - the variety Goral (Slovenia); 4 - the variety Azulena (Russia); 5 - the variety Zlaty Lan (Poland); 6 - the variety Perlyna Lisostepu (Ukraine). Some non-varietal material, in fact the edaphic ecotypes, were included to the study: 7 - from manufacturer Gold Garden (Ukraine) further - the ecotype Gold Garden; 8 - from manufacturer Seed Era (Ukraine) further - the ecotype Seed Era. The experiment was repeated three times.

Dry seeds were exposed with the dose $10 \mathrm{~Gy}$, dose rate $1.42 \times 10^{-2} \mathrm{~Gy} / \mathrm{sec}$ using the X-ray installation RUM-17 (Russia). UV-C exposure with the dose $10 \mathrm{~kJ} / \mathrm{m}^{2}$, dose rate $3.4 \mathrm{~W} / \mathrm{m}^{2}$ was 
carried out using the installation OBM-150 M (Ukraine) with two lamps Philips Special TUV $30 \mathrm{~W}$ (the Netherlands).

The research was conducted using some plant material, the methodology of obtaining the material was given in the previous report (Sokolova et al., 2021). The determination of X-ray exposure dose was based on the investigation of the medicinal plants conducted before. The results were assigned with the patent (Shylina et al., 2018). The dose curve of UV-C exposure is in the text.

The extraction of flavonoids and phenols was performed according to the generally accepted methods (Croft, 1998). The dry flower mass $(50 \mathrm{mg}$ ) was homogenized and macerated in $5 \mathrm{ml}$ of $70 \%$ ethanol at $24^{\circ} \mathrm{C}$ for $72 \mathrm{~h}$, then filtered, the amount of filtrate was adjusted to the initial volume by $70 \%$ ethanol and centrifuged. $0.5 \mathrm{ml}$ of a $2 \%$ solution of aluminum chloride was added in $50 \%$ ethanol and $2 \mathrm{ml}$ of $70 \%$ ethanol to $0.5 \mathrm{ml}$ of the extract and mixed. The reference solution contained $0.5 \mathrm{ml}$ of the extract, 1 drop of acetic acid and $2.5 \mathrm{ml}$ of $70 \%$ ethanol. The determination of the flavonoid content was performed by forming a yellow colored complex of the flavonoid-aluminum. After 20 min of the incubation, the optical density of the solution was measured on a SF-46 spectrophotometer at a wavelength of $410 \mathrm{~nm}$ against a reference solution, and the concentration of total flavonoids content was determined according to the rutine calibration graph and expressed in mg of rutine per $g$ of dry weight (DW). The total phenols content was determined from the same extract as flavonoids. $0.5 \mathrm{ml}(1 / 10$ of diluted by distilled water) Folin-Ciocalteu reagent and $1 \mathrm{ml}$ of distilled water were added to $0.1 \mathrm{ml}$ of the extract, mixed and kept at room temperature for 1 minute. After $1 \mathrm{~min}, 1.5 \mathrm{ml}$ of $20 \% \mathrm{Na}_{2} \mathrm{CO}_{3}$ water solution was added, mixed, and incubated in the dark for 2 hours at room temperature. The optical density of the blue solution was determined at a wavelength of $760 \mathrm{~nm}$ on a spectrophotometer against a sample containing $0.1 \mathrm{ml}$ of $70 \%$ ethanol instead of extract and expressed in mg of gallic acid (GA) (according to the calibration graph) per g DW. Statistical analyzes were performed by standard methods.

\section{RESULTS and DISCUSSION}

The study of dose curve under UV-C pre-sowing exposure by the secondary metabolite yield in the inflorescence indicated some dependence on the dose not only through the antioxidants yield but also in the dynamics of the index change. For example, the highest flavonoid yield after the exposure with $5 \mathrm{~kJ} / \mathrm{m}^{2}$ was indicated on the $62^{\text {th }}$ day after the sowing. For the phenols the highest index was indicated on the $54^{\text {th }}$ day after the sowing (Figure 1 ). In the inflorescences of the plants from the exposed with $1 \mathrm{~kJ} / \mathrm{m}^{2}$ seeds the highest secondary metabolites yield was shown on the $70^{\text {th }}$ day after the sowing. The index was lower than another one under $5 \mathrm{~kJ} / \mathrm{m}^{2}$ radiation exposure. The maximum yield of the flavonoids and phenols under $10 \mathrm{~kJ} / \mathrm{m}^{2}$ exposure was indicated on the $58^{\text {th }}$ and $97^{\text {th }}$ days after the sowing. In general, the dependence of the maximum accumulation of the antioxidants on the dose was non-monotonic, which was typical for the field of small doses. 
Figure 1. Dose-response curve of the flavonoids and phenols content in the chamomile inflorescences. Perlyna Lisostepu variety.
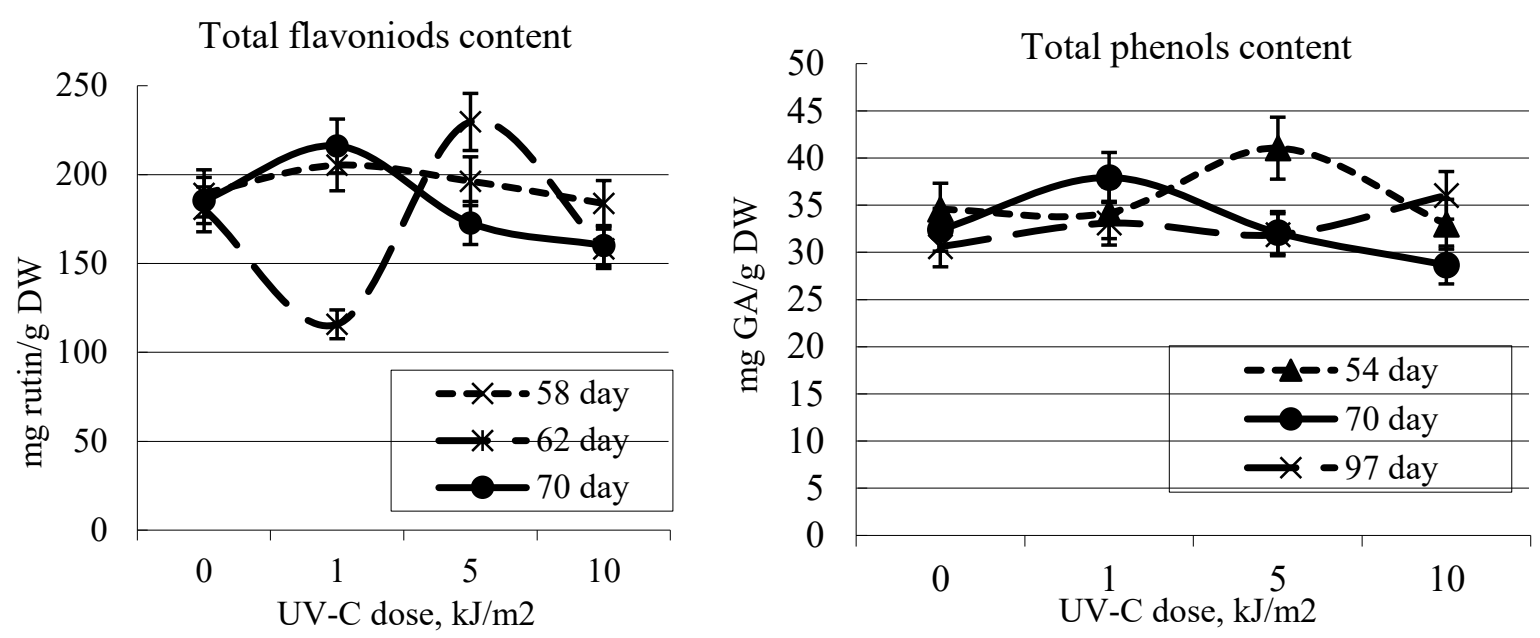

According to the estimation (Figure 2) there were major differences between the flavonoid yield in the dry mass of florescence of control variants through 8 chamomile genotypes. The highest initial yield of the antioxidant was indicated for Azulena and Goral varieties, the lowest one - for both Zlaty Lan variety and ecotype Golden Garden. Mostly through the control variants of all genotypes, except for the Zlaty Lan, the highest flavonoid yield was observed at the beginning of the flowering during the first selection of the medicinal raw material with the lowest harvest yield.

There were significant differences in the reaction of the different genotypes under the UV$\mathrm{C}$ and $\mathrm{X}$-ray exposure. The accumulation of flavonoids for almost all variants was nonmonotonic both in control and under radiation exposure. Two maximum flavonoid yields were indicated in the inflorescences of the mutant Perlyna Lisostepu grown from the UV-C exposed seeds on the $62^{\text {nd }}$ and $77^{\text {th }}$ days from the sowing. The same maximum index for varieties Quedinburg and Goral was shown on the $55^{\text {th }}$ day under the X-ray exposure and on the $70^{\text {th }}$ day under the UV-C one. The maximum flavonoid yield under the X-ray exposure of the Azulena variety seeds was on the $77^{\text {th }}$ day after the sowing. The same maximum index for the variety Zlaty Lan was indicated on the $70^{\text {th }}$ day under the UV-C exposure.

The maximum flavonoid yield under the X-ray exposure of the Perlyna Lisostepu variety seeds was on the $58^{\text {th }}, 70^{\text {th }}$ and $77^{\text {th }}$ days after the sowing. The maximum flavonoid yield under the X-ray exposure of the ecotype Golden Garden seeds was on the $70^{\text {th }}$ day after the sowing and on the $62^{\text {nd }}$ day under the UV-C exposure.

From the practical point of view, it was important that the increasing flavonoid yield through the exposed variants coincided with the maximum formation of the inflorescences. This effect was not indicated for the control. 
Figure 2. Total flavonoids content in the chamomile inflorescences of the different genotypes: 1 - the generative generation of the mutant Perluna lisostepu, 2 - the Quedlinburg, 3 - the Goral; 4 - the Azulena, 5 - the Zlaty Lan, 6 -the Perlyna Lisostepu, 7 - the Golden Garden, 8 - the Seed Era.

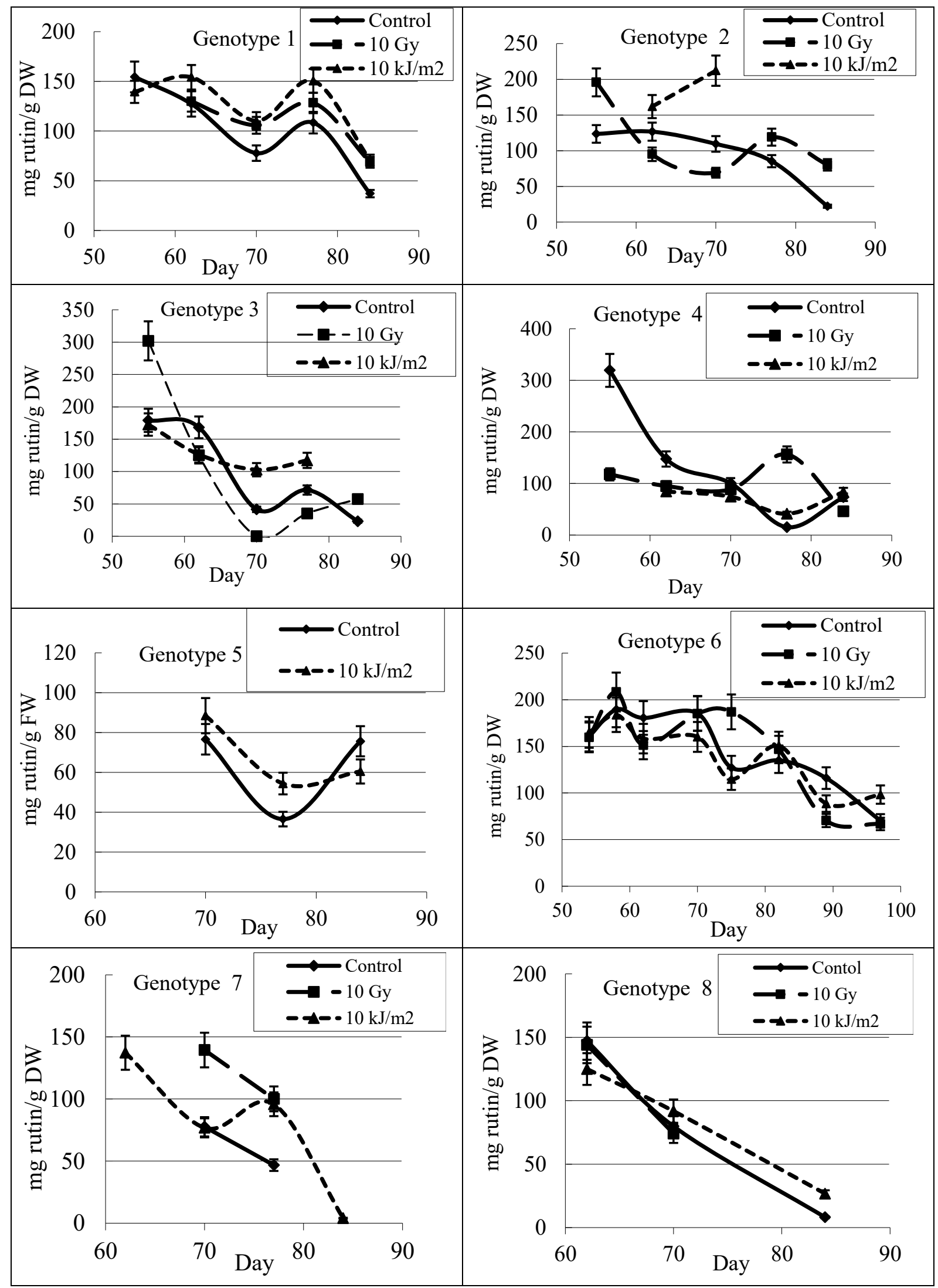


Experimental chamomile varieties were diverse with the yield of the phenols in the inflorescences. The maximum yield was indicated for Azulena, the lowest one - for Zlaty Lan (Figure 3). The pre-sowing UV-C exposure of the chamomile showed the increasing phenol yield in the inflorescences of the Quedlinburg variety and the mutant Perlyna Lisostepu and its decreasing yield for the Goral and Azulena varieties. The X-ray exposure led to increase in phenol yield in the inflorescences of the varieties Goral and Perlyna Lisostepu and the ecotype Golden Garden.

Figure 3. Total phenols content in the chamomile inflorescences of the different genotypes: 1 - the generative generation of the mutant Perlyna Lisostepu, 2 - the Quedlinburg, 3 - the Goral; 4- the Azulena, 5 - the Zlaty Lan, 6 - the Perlyna Lisostepu, 7 - the Golden Garden, 8 - the Seed Era.

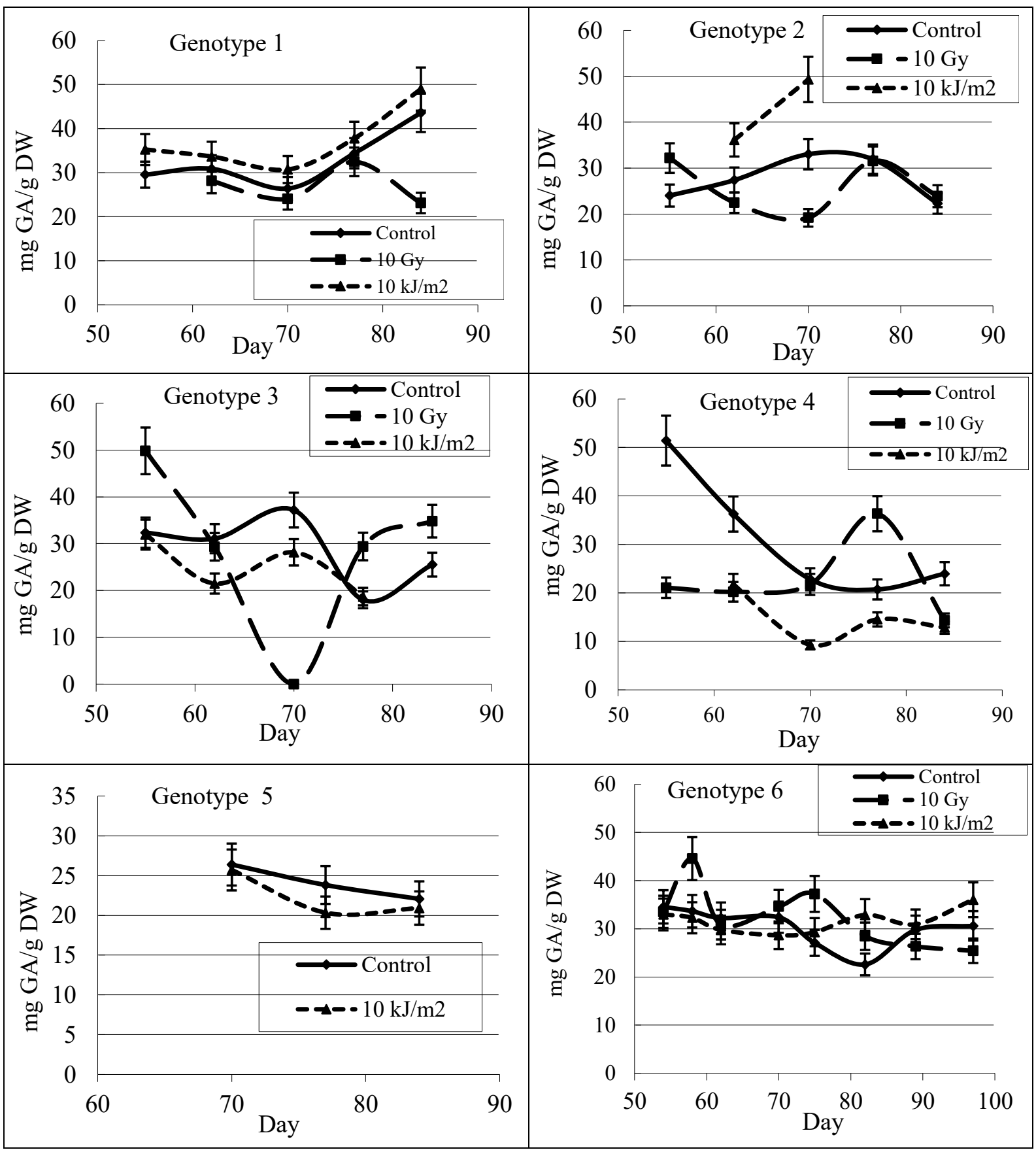




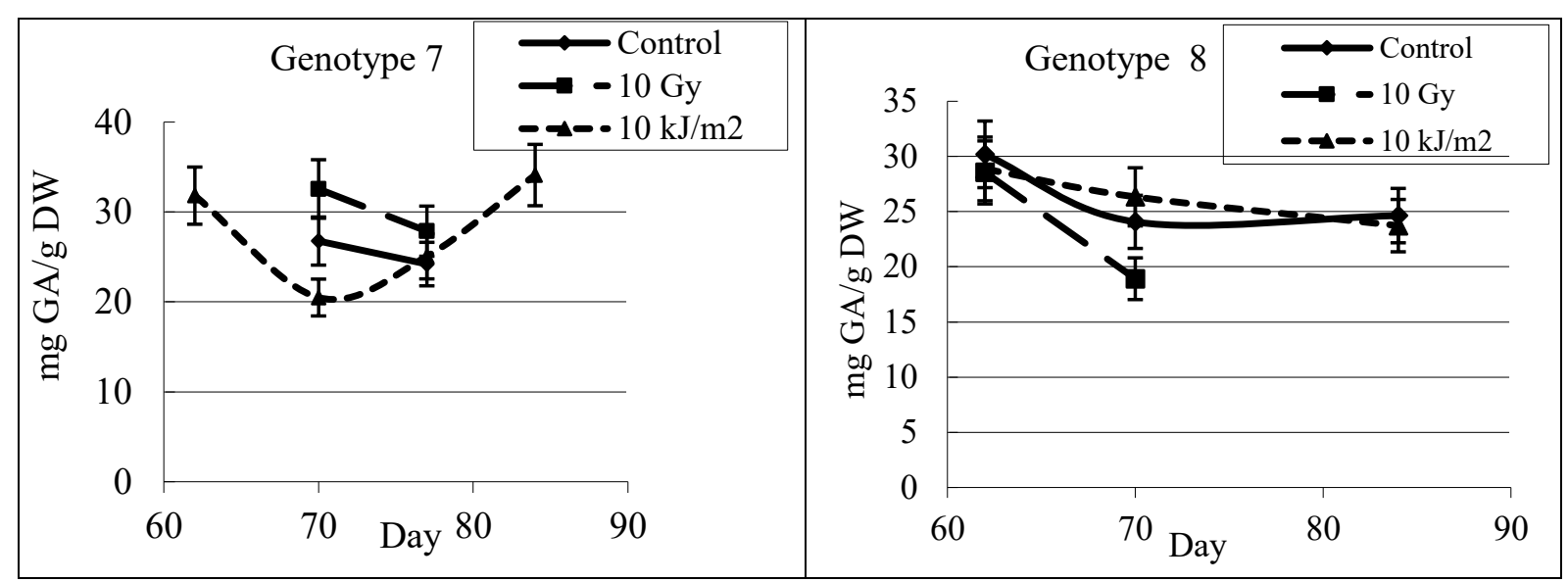

In general, UV-C and X-ray exposure did not cause major differences of the phenol content in the medicinal material. Under the UV-C exposure there was some increasing phenol yield for the variety Quedlinburg and the mutant Perlyna Lisostepu. The varieties Goral and Azulena demonstrated decrease of the index. There was increase in the phenol yield for Goral variety under the pre-sowing X-ray exposure. One of the key issues in the assessment and practical implementation of the pre-sowing radiation exposure effects is to study the connection between antioxidant yield in the control material and under the stress factor effect. The estimation of the correlation between the flavonoid yield in the control and UV-C exposed variants is $\mathrm{R}=0.63$ insignificant at this small sample. The correlation between the flavonoid yield in the control and $\mathrm{X}$-ray exposed variants is $\mathrm{R}=0.84$ with the significance level 0.05 .

The correlation between the phenol yield in the control and UV-C exposed variants is absent, $\mathrm{R}=0.22$. The correlation between the phenol yield in the control and $\mathrm{X}$-ray exposed variants is average $\mathrm{R}=0.59$ - insignificant at this level of the degrees of freedom.

Summarizing the results, we have concluded that not all the genotypes responded to the various radiation exposure in the right direction for the practice. Some non-variety seeds, i.e. randomly chosen ecotypes, did not show the effective increasing marker metabolite. The most effective relative flavonoid increase were varieties: the Perlyna Lisostepu, the Quedlinburg, the Goral and the mutant Perlyna Lisostepu. The calculation of the Pearson's linear correlation is quite informative when selecting genotypes for some biotechnological research.

The applied research is based on numerous theoretical findings that have caused changes in the paradigm of modern radiobiology and have shifted research directions towards low doses (1-2 orders of magnitude below the $\mathrm{LD}_{50}$ for a species) and non-targeting effects. The application of radiation in the range of medium and high doses in biotechnology also stimulated protective mechanisms (Harrison \& Were, 2007; Moghaddam et al., 2011), but could lead to the loss of crops of medicinal raw materials.

\section{CONCLUSION}

The obtained results are still far from the practical application. Nevertheless, they contain the answers to a number of questions, the solution of which is necessary for the implementation in practice.

First, pre-sowing low-dose UV-C and X-ray radiation exposure of seeds leads to significant changes in primary and secondary metabolism. The marker of the first one is the differences in growth processes and in the yield of chamomile inflorescences shown earlier. The marker of the second one is the changes in flavonoid and phenol accumulation. Both changes are characterized with a non-targeted nature, in other words, they are observed in organs that were not directly exposed. Radiation exposure of dry seeds is technologically easier than the 
exposure of seedlings, plants or their organs. The response to both types of the exposure is specific by variety and a simple principle of variety selection to stimulate secondary metabolism has been proposed.

Second, the study indicates the possibility to increase the medicines yield due to the simultaneous increasing yield of the medicinal raw material and the specific content of the target metabolite. This forms the basis to use the systemic effects of the ionizing and nonionizing radiation exposure in the pharmacology.

\section{Acknowledgments}

This work was supported by funding Scientific Investigative Projects NAS of Ukraine by project 1230/3 "Studying the effect of biotic and abiotic stress factor exposure to the accumulation of secondary metabolites and recombinant compounds in genetically modified and native plant systems".

\section{Declaration of Conflicting Interests and Ethics}

The authors declare no conflict of interest. This research study complies with research and publishing ethics. The scientific and legal responsibility for manuscripts published in IJSM belongs to the authors.

\section{Authorship Contribution Statement}

Author 1: Investigation, Methodology, Visualization, Software, Formal Analysis. Author 2: Investigation, Methodology, Visualization, Software, Formal Analysis and Writing original draft. Author 3: Investigation, Methodology, Visualization, Supervision, Validation and Writing original draft. Author 4: Methodology. Author 5: Resources. Author 6: Supervision.

\section{Orcid}

Vladyslav Zhuk (D) https://orcid.org/0000-0003-1966-7537
Daryna Sokolova (D) https://orcid.org/0000-0002-4540-0177
Alexandra Kravets (D) https://orcid.org/0000-0002-4979-5022
Volodymyr Sakada (iD https://orcid.org/0000-0002-9142-3660
Ludmila Glushenko (iD https://orcid.org/0000-0003-2329-5537
Mykola Kuchuk (iD https://orcid.org/0000-0001-7365-7474

\section{REFERENCES}

Alothman, M., Bhat, R., \& Karim, A. (2009). Effects of radiation processing on phytochemicals and antioxidants in plant produce. Trends in Food Science \& Technology, 20(5), 201-212. https://doi.org/10.1016/j.tifs.2009.02.003

Aziz, Z., Tang, W., Chong, N., \& Tho L. (2015). A systematic review of the efficacy and tolerability of hydroxyethylrutosides for improvement of the signs and symptoms of chronic venous insufficiency. J. Clin. Pharm. Ther., 40(2), 177-18. https://doi.org/10.1111/jcpt.122 $\underline{47}$

Cermak, R., \& Wolffram S. (2006). The potential of flavonoids to influence drug metabolism and pharmacokinetics by local gastrointestinal mechanisms. Curr. Drug Metab., 7, 729-744. https://doi.org/10.2174/138920006778520570.

Clark, J., Zahradka, P., \& Taylor C. (2015). Efficacy of flavonoids in the management of high blood pressure. Nutr. Rev. 73(12), 799-822. https://doi.org/10.1016/j.coph.2019.04.014

Croft, K. (1998). The chemistry and biological effects of flavonoids and phenolic acids. Annals of the New York Academy of Sciences, 854(1), 435. https://doi.org/10.1111/j.1749-6632.19 98.tb09922.x 
Dai, J., \& Mumper, R. (2010). Plant phenolic: extraction, analysis and their antioxidant and anticancer properties. Molecules, 15(10), 7313-7352. https://doi.org/10.3390/molecules151 07313

Gould, K., \& Lister, C. (2006) Flavonoid functions in plants. In Book Flavonids. Chemistry, biochemistry and applications, $1^{\text {st }}$ ed. Boca Raton, Florida, USA: CRS Press. ISBN 9780849320217.

Harrison, K., \& Were, L. (2007). Effect of gamma irradiation on total phenolic content yield and antioxidant capacity of almond skin extracts. Food Chemistry, 102(3), 932-937. https://doi.org/10.1016/j.foodchem.2006.06.034

Kaur, S., \& Mondal, P. (2014). Study of total phenolic and flavonoid content, antioxidant activity and antimicrobial properties of medicinal plants. J Microbiol Exp, 1(1), 1-6. https://doi.org/10.15406/jmen.2014.01.00005

Khattak, K. \& Simpson, D. (2008). Effect of gamma irradiation on the extraction yield, total phenolic content and free radical-scavenging activity of Nigella sativa seed. Food Chemistry, 110(4), 967-972. https://doi.org/10.1016/j.foodchem.2008.03.003

Kravets, A., Wengzhen, G., \& Grodzinsky, D. (2009). Remote interaction of irradiated and unirradiated plants. Radiation Biology. Radioecology, 49(4), 490. (in Russian).

Kretovich, V. (1986) Plant Biochemistry. Moskow, Russia: Vusha Shkola.

Kudryashov, Y. (2001). Basic principles in radiobiology. Radiation Biology. Radioecology, 41(5), 531. PMID: 11721348.

Kuzin, A. (1970) Structural and metabolic hypothesis in radiobiology, $1^{\text {st }}$ ed. Moscow, Russia: Nauka.

Little, D. (2007). The unintended effects of ionizing radiation: conclusions regarding low-dose effects. Radiation Biology. Radioecology, 47(3), 262. (in Russian)

Mittler, R. (2002). Oxidative stress, antioxidants and stress tolerance. Trends Plant Sci., 7, 405 - 410. https://doi.org/10.1016/s1360-1385(02)02312-9.

Moghaddam, S., Jaafar, H., Ibrahim, R., Rahmat, A., Aziz, M., \& Philip, E. (2011). Effects of acute gamma irradiation on physiological traits and flavonoid accumulation of Centella asiatica. Molecules, 16(6), 4994 - 5007. https://doi.org/10.3390/molecules16064994

Sengul, M., Yildiz, H., Gungor, N., Cetin, B., Eser, Z., \& Ercisli, S. (2009). Total phenolic content, antioxidant and antimicrobial activities of some medicinal plants. Pak. J. Pharm Sci., 22(1), 102 - 106. PMID: 19168430.

Shylina, Y., Pchelovska, S., Lytvynov, S., Sokolova, D., Zhuk, V., Lystvan, K., Nesterenko, O., Salivon, A., \& Tonkal, L. (2018). Patent of Ukraine № 129749. Kyiv, Ukraine. Patent and trademark office. Retrieved from https://ukrpatent.org/uk/articles/bases2

Sokolova, D., Kravets, A., Zhuk, V., Sakada, V., Gluschenko, L., \& Kuchuk, M. (2021). Productivity of medicinal raw materials by different genotypes of Matricia Chammomila L. is affected with pre-sowing radiation exposure of seeds. International Journal of Secondary Metabolite, 8(2), 127-135. https://doi.org/10.21448/ijsm.889817

Treutter, D. (2006). Significance of flavonoids in plant resistance: a review. Environ. Chem. Lett., 4(3), 147 - 157. https://doi.org/10.1007/s10311-006-0068-8

Winkel-Shirley, B. (2002). Biosynthesis of flavonoids and effects of stress. Curr. Opin. Plant. Biol., 5, 218-223. https://doi.org/10.1016/s1369-5266(02)00256-x 